\title{
A Four-Year Biomedical Engineering Design Curriculum Assessment and Improvement
}

\author{
John D. Gassert, Ph.D., P.E. \\ Milwaukee School of Engineering
}

\begin{abstract}
The MSOE BE faculty members believe that design cannot be taught in just one year. Learning design takes practice and time. They believe that the best approach for educating students in the practice of design is through a four-year design curriculum. The 2002 entering freshman class marks the beginning of the tenth offering of the four-year design curriculum. The assessment process has demonstrated the value of the four-year program. It has also resulted in modifications in the way in which the design sequence is presented. This paper will describe the four-year design curriculum, the assessment process, and the improvements that have been made to the curriculum as a result of assessment.
\end{abstract}

Introduction

When and how should design be taught? Should it be taught in one semester, a year, or four years? What tools should be incorporated? How should it be assessed? To answer these questions, one must first look at program goals and objectives. One must also examine external requirements.

The biomedical engineering (BE) faculty members and the program's industrial advisory committee have established a goal for the design component of the biomedical engineering curriculum at the Milwaukee School of Engineering (MSOE). That goal is to provide students with the tools needed to practice the profession of biomedical engineering after graduation. Those tools or outcomes include the ability to:

- develop an understanding of the engineering design process and learn that it is not trial and error.

- apply engineering topics, and topics in the life sciences, mathematics, physics, chemistry, and the social sciences, to the design process;

- apply team-building concepts;

- develop and apply project management;

- understand of the role of regulatory agencies;

- develop skills in written and oral communications.

- develop and maintain an engineering design logbook.

- recognize the need for courses in their curriculum. 
Criterion 4 of the Criteria for Accrediting Engineering Programs published by the Engineering Accreditation Commission, Accreditation Board for Engineering and Technology has established specific requirements for biomedical engineering design education. This criterion states "Students must be prepared for engineering practice through the curriculum culminating in a major design experience based on the knowledge and skills acquired in earlier course work and incorporating engineering standards and realistic constraints that include most of the following considerations: economic; environmental; sustainability; manufacturability; ethical; health and safety; social; and political."

The goals that were defined for the program and the constraints that were placed on the program by ABET begged the question; How/When Should Design Be Taught? Dutson, et. al., reviewed over 100 papers that described the design curriculum at universities across the country. Although Dutson reported inclusion of design aspects in various curricula as early as the freshman year, without exception, the capstone design courses were begun in the senior year. ${ }^{2}$ This was also the practice at MSOE and remains the practice for all engineering programs at MSOE except for BE. The BE faculty concluded that design cannot be taught in just one year. Learning design takes practice and time. As a result, in 1992, the MSOE faculty introduced a BE curriculum that included a four-year capstone project. ${ }^{3}$

The BE faculty believe that the four-year design process is important for two reasons. First it gave students time to learn and understand the importance of the design process. Secondly, it provides a valuable assessment tool whereby the BE faculty can assess student learning not only for design but also for other curriculum outcomes. ${ }^{3}$ The roll of the capstone design course for assessment and continuous quality improvement has also been reported by the faculty at other universities. 4,5

\section{The Curriculum and the Design Process at MSOE}

The BE design program at MSOE is the eleven-quarter course sequence. Beginning in the winter quarter of the freshman year and continuing over the subsequent eleven quarters, the $\mathrm{BE}$ student is required to demonstrate that he or she possess the design skills necessary to succeed. As with the development of any skill, practice is the key to success. The objective of this engineering design experience is to prepare the MSOE BE student to practice the profession of engineering after graduation. This is accomplished simulating a "real-world" industrial situation.

To simulate a "real-world" industrial situation, students are required to apply for one or more of the following positions on a design team: Group Manager, Project Manger, Associate Project Manager, or Project Engineer. The teams are then assigned "open-ended" design projects. For example, one year's design teams were required to develop educational aids for training medical professionals; two groups were asked to design an aid for critical care education, two for intermediate care, and two for home care. Resulting projects included manikins to teach proper placement of ECG electrodes, manikins that provide simulation of heart sound, bowel sound, and intracranial pressure and a neonatal intensive care simulation. Students also developed a method for the measurement of blood flow in the coronary arteries using far- 
infrared thermography. These projects and others can be observed on the MSOE BE program home web page at www.msoe.edu/be.

The Biomedical Engineering curriculum also provides the high level of education and practice that is required to become a Professional Engineer. The educational component of courses in engineering, mathematics, sciences, communications, humanities, social science, business and law, serves the overall needs of the student seeking to achieve professional status. The practical component is composed of the many laboratories and the more than 24 credits of engineering design contained in the curriculum. As the student moves through the curriculum, he/she is expected to apply the knowledge gained in each course to the solution of a particular biomedical engineering design problem.

Assessment

Continual and progressive assessment of a student's progress is crucial to the success of the design team. It is also necessary for continual curriculum improvement. The assessment processes include clearly defined "Engineering Design Policies and Procedures," regularly scheduled meetings with the design teams, scheduled formal and informal oral reports, formal and informal design reviews, and evaluation of the students' use of an engineering logbook. All of these tools document performance and provide a record for assessment. Assessment is performed over the eleven-quarter design sequence of the BE curriculum at MSOE.

The engineering logbook is one of the most valuable assessment tools. All students are expected to maintain an engineering logbook beginning in the freshman year. This logbook is evaluated by the BE faculty every quarter. A student's growth can quickly be evaluated by examining a logbook that has been used for four years.

The scheduled formal presentations provide valuable feedback on a student's ability to communicate and on his or her understanding of material covered in courses throughout the curriculum. Design teams are expected to make formal presentations that are video taped and evaluated by the BE faculty and the English department faculty. They are also expected to submit written formal reports. Comparing reports from prior years with the current submission assesses a student's growth.

The primary assessment of the design process is accomplished in the junior and senior years. In the second quarter of the junior year, each team presents a written and oral report on their progress to the faculty, students and invited guests. The report must include a product description, system functional specifications, a market analysis, and a financial analysis. All BE faculty and the invited guest evaluate each team's performance and the students receive that feedback. The specifications that were presented at the junior design show are refined into subsystem design specifications following the show. A prototype is developed during the senior year. This process culminates in a design show in which the products and design are judged. The design teams' performance is used by the BE faculty to improve the design process of design teams in subsequent years. 


\section{Curriculum Improvements}

Examples of process improvement include the inclusion of several design reviews during the senior year. During the initial implementation of the curriculum, formal design reviews were not scheduled. The assessment process identified this as a problem and at least two formal design reviews where all $\mathrm{BE}$ faculty members question design decisions are scheduled during the senior year. Another change that resulted from the assessment process was the inclusion of credit for design during the sophomore and junior years. In the original BE curriculum, students did not receive credit for their design work until the spring quarter of the junior year. The students were expected to include design work as part of their other BE coursework. Although students were willing to do this they recommended that specific design credit be included earlier in the curriculum. This change was implemented four years ago and the change is currently being assessed. Although it has appears to be a better situation for the students, it has created a significant scheduling problem for the faculty who must team-teach the design sequence.

The assessment process has identified another weakness in the design sequence. Students often have not fully defined product specifications until well into their senior year. As a result students have difficulty properly scheduling their time and they spend many late nights as they prepare for their senior design show. Therefore, a planned improvement is the inclusion of a specification review in the spring quarter of the junior year. The intent would be to force design decisions earlier in the process.

Project management also has a significant impact on the students' ability to plan. With the change to offering credit in the curriculum, the number of lectures on formal project management was reduced. This change has likely reduced the students' ability to plan appropriately. This year, freshman students have been introduced to "time management" and "time tracking" as suggested by Watts Humphrey. ${ }^{6}$ The students will be expected to use these concepts and other time management concepts that will be introduced in future lectures to refine their project management skills.

\section{Conclusion}

An annual survey of graduates who graduated one year and five years ago is one of the tools used to assess the effectiveness of the four-year design curriculum. Another tool is an exit interview of current graduates. The results of this assessment is that the BE faculty, program graduates, employers, and members of the industrial advisory committee believe that the four year design is a uniquely valuable experience. Graduates of the MSOE BE program are prepared exceptionally well for design. The MSOE BE faculty considers the design sequence successful.

\section{References:}

1. "Criteria for Accrediting Engineering Programs," Engineering Accreditation Commission, Accreditation Board for Engineering and Technology, Inc. 111 Market Place, Suite 1050, Baltimore, MD 21202. 
2. Dutson, A. J., Todd, R. H., Magleby, S. P., Sorensen, C. D., “A Review Of Literature On Teaching Engineering Design Through Project-Oriented Capstone Courses," Journal of Engineering Education, Vol. 86, No. 1, January 1997, pp. 17-28.

3. Gassert, J.D., Canino, V.C., "Four Year Biomedical Engineering Design At The Milwaukee School Of Engineering," Proceedings, ASEE Annual Conference, 1999, Session 3409.

4. Napper, S. A., Hale, P. N., "Using Design Projects for Program Assessment," Journal of Engineering Education, Vol. 88, April 1999, pp. 169-172.

5. $\quad$ Lyons, J. S., Bayoumi, A.M., "CQI Processes, Results, and Program Improvements for Engineering Design," IEEE Transactions on Education, VOL. 43, no. 2, pp. 174-181, MAY 2000.

6. Humphery, W. S., "Introduction to the Personal Software Process," Addison-Wesley Longman, Inc., Reading, MA, 1997.

JOHN D. GASSERT, Ph.D., P.E.

John Gassert is currently a Professor and Vice Chairman of the Electrical Engineering and Computer Science Department at Milwaukee School of Engineering. He received his Ph.D. in Biomedical Engineering in 1995 and his MS degree in Electrical Engineering in 1974 both from Marquette University. Gassert is a Senior Member of the IEEE and an ABET EAC program evaluator for Biomedical Engineering. He has developed and taught courses at both the graduate and undergraduate level in Biomedical Engineering, Medical Informatics, Perfusion, Electrical Engineering, Computer Engineering, and Electrical Engineering Technology. Prior to arriving at MSOE, Gassert spent seventeen years in industry in positions as a design engineer, a clinical engineer and a consultant.

Proceedings of the 2003 American Society for Engineering Education Annual Conference \& Exposition Copyright (C) 2003, American Society for Engineering Education 